\title{
A Study on the Necessity of Promoting "National Primary and Secondary School Students Martial Arts Aerobics" in Primary and Secondary School
}

\author{
Zhou Minghua \\ Sport University \\ Luoyang Normal University \\ Luoyang, Henan Province, China \\ lync-zhmh@163.com
}

\author{
Cheng Nan \\ Sport University \\ Luoyang Normal University \\ Luoyang, Henan Province, China \\ chengnan1107@163.com
}

\begin{abstract}
Chinese martial art has a long history and embodies the wisdom of Chinese nation. As an important part of Chinese traditional culture, martial art is the treasure of Chinese culture and the important content of $P E$ teaching in primary and secondary schools. It has the important value of enhancing the cohesion of Chinese nation and promoting and cultivating the Chinese national spirit. Promote martial art in primary and middle schools in the form of broadcast exercises with the guiding concept of inheriting martial arts and traditional Chinese culture, promoting and nurturing Chinese national spirit. It not only enriches the teaching content of the school, but also increases students' exercise types and enhances the physical and mental health of children and adolescents in China, while promoting and disseminating martial arts. Martial art aerobics can't only deepen students' understanding of martial arts, strengthen their correct understanding of martial art, but also arouse students' interest and enthusiasm in martial arts and promote the further development of martial arts in primary and secondary schools, promoting and nurturing Chinese national culture and spirit. This function of martial art aerobics can't be replaced by other class-break setting-up exercises.
\end{abstract}

Keywords-Martial Art Aerobics, Primary and Secondary Schools, Promotion, Martial Art Education

\section{INTRODUCTION}

As an important part of Chinese traditional culture, martial art is the treasure of Chinese culture and the important content of PE teaching in primary and secondary schools. Martial art education in primary and secondary schools is related to the inheritance and development of martial art culture and the future of the nation. As early as the Revolution of 1911, some people of insight in martial art and education circles have put forward: China's fencing, guns, bow and riding are best sports. They advocate using them as the content of school PE lesson, and "replacing western gymnastics." In October 1918, the Ministry of Education held a national meeting of secondary school principals and passed a resolution: "All middle schools in the country should add martial art to their education content." However, the situation of martial art education is not optimistic nowadays. Current martial art education, especially the status of martial art education in primary and secondary schools, really concerns us: martial art is getting far away from the classroom of primary and secondary schools. Olympic athletic events and martial art events from other Asian countries have become the sports fashion that primary and secondary school students are chasing. Now promote martial art in primary and middle schools in the form of broadcast exercises with the guiding concept of inheriting martial arts and traditional Chinese culture, promoting and nurturing Chinese national spirit. It not only enriches the teaching content of the school, but also increases students' exercise types and enhances the physical and mental health of children and adolescents in China, while actively promoting and disseminating martial arts. It provides basic need for promoting martial art aerobics into the primary and secondary schools.

\section{INHERIT MARTIAL ARTS AND TRADITIONAL CHINESE Culture, Promote and Nurture Chinese NATIONAL SPIRIT}

In 2009, President Hu Jintao visited the Chinese Cultural Center in Mauritius and said, "Firstly learning martial art can build your body; secondly it can let you understand Chinese culture; thirdly it can enhance the friendship between Chinese and Mauritians." These words have shown us the sports and cultural values of martial art. The promotion of martial art aerobics can fundamentally change the backwardness of martial art education in primary and secondary schools, so that the problem of martial art education in schools which has concerned people for a long time can be truly implemented. The beneficiaries of this exercise will be the majority of students who are eager to learn martial art. They not only can learn the ability of bodybuilding and self-defense from it, but also can develop their indomitable will. More importantly, they can enhance their national pride through the national culture influence of martial art.

Confucian philosophy emphasizing "benevolence, righteousness, courtesy and faith" has deeply influenced the Chinese martial art's ethical thought and became its foundation and core. Through the martial art education, students can enhance the humanistic qualities, focus on the improvement of personal qualities, and maintain a good attitude in the face of competition. At the same time, harmony is the unique value orientation of martial art. Martial art culture sees harmony of human body and mind as the true, interpersonal harmony as the good and harmony between man and nature as the beautiful. 
Harmony constitutes the foundation of martial art culture development. Take advantage of martial art culture to let students comprehend the essence of thought of martial art culture "unity of heaven and man", and get to know the way of harmony. Let students behave according to the value that "now the humane man, wishing himself to be established, sees that others are established, and, wishing himself to be successful, sees that others are successful.", and learn to care and respect other people. Encourage them to make a contribution to the society and other people, and achieve the value of their own lives, laying a solid foundation for the establishment of a harmonious society.

From the perspective of the responsibility and obligation of cultural heritage and cultural inheritance, we should fully find the cultural value of traditional national culture and martial art culture from the strategic height of carrying forward national cultural spirit, pay much attention to the popularization and education of traditional national sports and martial art culture. We can learn from Japan and South Korea about their way to inherit national culture, and choose to fully implement the $2+1$ curriculum model in school physical education curriculum setting, setting two PE classes and one traditional national PE class per week for primary school physical education. It's aimed to strengthen the education of national spirit and culture, and consolidate the foundation of national culture in the majority of children and adolescents. If the martial art aerobics is implemented, it will have a strong response in the majority of children and let many young children come out from the loss of learning taekwondo and karate, making children reunderstand the charm of Chinese martial art in martial art education and improving their national pride. Martial art aerobics has the traditional characteristics of the Chinese nation and contains many fine traditions of the Chinese nation. For the primary and middle school students, the culture which is taught first can be preconceived, forming a solid and durable cultural acceptance basis. It helps to foster the national spirit of the Chinese people, enhance the national outstanding cultural identity and self-confidence of the majority of young people, and stimulate their enthusiasm for learning martial arts. Martial art aerobics not only can deepen students' understanding of martial art, strengthen the correct understanding of martial art, but also can arouse students' interest in martial art and promote the further development of martial art in primary and secondary schools, so as to carry forward national culture and nurture national spirit. This function of martial art aerobics can't be replaced by other class-break setting-up exercises.

\section{ENRICH SCHOOL TEACHING CONTENT AND ADD STUDENT EXERCISE TYPE}

After the founding of new China, criticism of attack and defense theory let martial art embark on the road of style-based development. As a result of one-sided pursuit of competitive high, difficult, beautiful and new, dance phenomenon has appeared in the competitive martial art style. The one-sided pursuit of common character of western sports leads to the loss of the essential characteristics of martial art. Under the influence of style-based theory, the teaching content of martial art in school is single, and the self-defense function of martial art has been weakened, reducing the charm of martial art. Current content of martial art education is far from adapting to the current educational situation. In recent years, under the guidance of PE and health curriculum standards, a variety of versions of primary and secondary physical education textbooks have been published, but most of the martial art content in them has followed the style content created in the middle of the last century. The textbooks not only significantly lag behind the development of the times, and their content lacks scientific level cohesion and have the phenomenon of simple repetition. The style-based teaching content can't highlight the characteristics of martial art. It not only can't get the recognition of physical education teachers, but also is difficult to stimulate students' interest in practicing it. What to teach has become the primary problem restricting the development of martial art education in primary and secondary schools.

According to the hierarchical division of martial art education content, the teaching content of primary and middle schools should develop students' interest in martial art and let them master the action techniques and use methods, so as to achieve the purpose of mobilizing students' enthusiasm of learning martial art and improving their health and self-defense skills. "National Primary and Secondary School Students Martial Arts Aerobics" takes Chinese martial art as its main content and expresses itself in the form of broadcast gymnastics. Under the guiding thought of passing on martial art and Chinese culture, promoting and cultivating the national spirit, it's aimed to enrich the exercise type of primary and secondary students, and enhance the physical and mental health of children and adolescents in China. Martial art aerobics has combined the bodybuilding and cultural characteristics. On the basis of highlighting the characteristics of national culture, it is created in line with the physical and psychological characteristics of primary and middle school students, and follows the basic rules of primary and secondary education and teaching.

Martial art aerobics has combined targeted and systematic principles in the creation. In terms of targeted principle, primary and secondary students from the different learning stages and regions have difference characteristics in physical structure, psychology and knowledge structure. Therefore, according to students' growing law, psychological characteristics, aesthetic characteristics and strength, flexibility, endurance, speed and sensitivity in different learning stages, as well as quality differences of students from areas, we have created four sets of martial arts aerobics, including "Rising Sun" and "Eyas Stretch its Wings" which are appropriate for primary students, and "Heroic Juvenile" and "Kungfu Youth" which are appropriate for secondary students. In terms of systematic principle, each set of martial art aerobics includes five basic technical elements of martial arts: play, kick, take, lean, and fall. Each single action has the corresponding attack and defense meanings. They can both be practiced alone or in pair, fully embodying the offensive and defensive characteristics of martial art. It improves practitioners' interest in learning. 


\section{Promote The DeVElopment AND COMmunicAtion of MARTIAL ART}

In the research literature of martial art communication, many studies on the longitudinal communication of martial art in schools often mention that school is an effective way of communication for martial art culture, school is the "main position" of the development of national traditional sports, the development and popularization of martial art itself must not ignore the important position of school. Both Japan's judo and South Korea's Taekwondo have improved the action and rules on the basis of maintaining its basic essence, making it more suitable as teaching training content and competition event, and use the school as the main channel to promote them to young people, so as to get more and more people to love it. Considering the proportion and popularization of national sports in school physical education in their country and judo Museums and Taekwondo Museums around the world, it is not difficult to understand that it's by no means accidental that these ethnic sports enter the Olympic Games on behalf of Asia. The school should not only become the promotion base of Olympic sports events, but also should take on the historical responsibility of developing national sports and carrying forward national culture. At the same time, as an ancient traditional sport, Chinese martial art has much incomparable superiority to other western sports. Today, with the full implementation of quality education, Chinese martial art culture has important educational function and significance. School sports should make martial art culture education an important part of it, and give full play to the role of martial art culture in the implementation of quality education in schools, so as to promote the comprehensive development of school sports.

Martial art aerobics is in line with martial art teaching content in primary and secondary schools, which helps speed up the process of socialization of martial art education. Martial art aerobics' actions are of various forms and funny. It can be used for self-defense. It can also inherit national culture and carry forward national spirit. In practicing, students can gradually improve their martial art skills, imperceptibly accept the education of martial art sentiment and etiquette patterns, so as to achieve the purpose of passing on martial art culture, nurturing and carrying forward the national spirit. Reduce the difficulty of actions, constantly summarize and find new laws in martial art teaching, so as to improve and enrich the teaching methods. Change concept and teaching mode, and pay attention to the cultivation of students' spirit by martial art. Combine patriotism with national spirit and martial art spirit, and pay more attention to the combination of teaching content and daily life. Use these ways to promote the communication of martial art culture in school.

\section{Promote the DeVelopment of Lifelong Sport}

With the deepening of the construction of a socialist welloff society, people's material standard of living is increasing and have higher requirement for the spiritual life. The pursuit of health, sports pleasure and getting rid of tense and fatigue in work and life has become people's basic requirement for fitness activities. As an outstanding traditional culture of the Chinese nation, the role of martial art can't be neglected in social life. Martial art not only has the function of keeping fit and healthy, but also has the function of cultivating sentiments and the mind. At the same time, as a cultural form, martial art has absorbed the philosophical thought of Taoism, Confucianism, Taoism and Buddhism, and is also related to traditional medicine, traditional aesthetics and various military tactics. It not only can provide specific practice methods for people's fitness activities, but also can improve people's fitness consciousness from the perspective of ideology and culture, and enhance people's life-long physical thinking of pursuing both physical and psychological health. School is the melting pot of personnel training. One or two decades later, the Chinese martial art will be all over the campus. Students' physical health will be improved, everyone will be high-spirited and in good fettle. Its impact is difficult to estimate. National Fitness Program requires "taking national people as the object of implementation, and focusing on young people and children." China's colleges and universities, secondary and primary schools are not only the learning corner to cultivate the reserve talents that China's modern construction cause needs, but also are a window to reflect the humanistic quality of our young people. And martial art aerobics content is more suitable for China's young people, promoting the development of lifelong sports.

\section{CONCLUSION}

As an outstanding national sport event of the Chinese nation, martial art has a strong value function in school culture education. It has been accepted and recognized by the Chinese people and the rest of the world and is being integrated into the world sports culture development. However, in the current communication of martial art in schools, we should objectively evaluate its characteristics, strengthen its heritage, and promote the localized education of martial art. We should take martial art as an entry point for the internationalization of China's national sports, and promote the international development of martial art. As the first set of "National Primary and Secondary School Students Martial Arts Aerobics" created by the government, it is of great value and significance, and is an important milestone in the development of martial art education in our country. Martial art aerobics is promoted in school mainly as a means of implementation and a carrier, not the ultimate goal. Our purpose is not only to conduct physical exercise. More importantly, in the face of today's cultural diversity caused by globalization, we should attach importance to the education of our young people and children in inheriting traditional culture, carrying forward and cultivating national spirit, and enhancing national cultural identity.

\section{REFERENCES}

[1] Created by Ministry of Education, Sports Health and Arts Education Division, and China's General Sports Administration, Martial Art Research Institute. Teacher Reference Book of National Primary and Middle School Students Martial Arts Aerobics. [M]. Beijing: Higher Education Press, 2010.9.

[2] Kang Gewu, Hong Hao. Survey Research of Martial Art Education in Primary and Secondary Schools In China[J]. Sports Science, Vol 29, No. 3.2009 . 
[3] Li Shengfu, Kou Jianmin, Yao Weihua, "The Function and Role of Martial Art in Serving the National Policy and Cultivating the National Spirit"[J]. Sports Science, 2005.1

[4] Shi Huabi, Zhai Shaohong. Educational Feature and Development Form of School Martial Art[J]. Xi'an Institute of Physical Education, Vol 27, No. 3.2010.5.

[5] Hong Hao. The Necessity of Introducing Martial Art Rank System into the Primary and Secondary School Teaching[J]. Journal of Beijing Sport University, vol. 33, No.7. 2010,7.
[6] Chang Zhaoli. The Main Problems and Countermeasures of Current School Martial Art Education [J] .Heilongjiang Historical Annals, 2009, 18.

[7] Shi Huabi. School Martial Art Education Multi-dimensional Integrated Teaching Model[J]. Physical Education, No.5. 2010.

[8] Wang Gang, Qiu Pixiang, Bao Lei. Reconstruction of School Martial Art Education System Must Strengthen the "Traditional Chinese Culture Consciousness."[J]. Journal of Physical Education, 2009.9 